\title{
Jovellanos e Ifigenia: Racine, Boscán y la tradición pictórica
}

Frederick A. de Armas

University of Chicago

Con el descubrimiento en 2007 de un nuevo manuscrito de Gaspar Melchor de Jovellanos por el padre Juan Bautista Olarte en el Monasterio de San Millán de Yuso, y su publicación, junto con varios ensayos, se puede apreciar esta obra perdida por siglos. Se trata de su juvenil traducción de la tragedia de Juan Racine, Iphigénie. Jovellanos, quien se dedicaba a la lectura y traducción de obras clásicas, trabajo que se fomentaba en la tertulia de Pablo de Olavide, pudo así a los 25 años completar esta traducción. El autor retoma el teatro francés para contrarrestar lo que para él son los excesos de la comedia y los entremeses del Siglo de Oro "que aficionan al teatro a la parte más ruda y sencilla del pueblo, deleitándola con las groseras y torpes bufonadas que forman todo su mérito"1. Juan Menéndez Peláez y Carla Menéndez Fernández explican: "Jovellanos creía en la impronta docente y la función didáctica y pedagógica que había de tener el teatro”2. Esta

1. Gaspar Melchor de Jovellanos, Espectáculos y diversiones públicas, ed. Guillermo Carnero, Cátedra, Madrid, 1997, p. 203. En términos político-sociales, Malcom K. Read asevera que Jovellanos intenta subyugar a la plebe, prohibir teatro vano y solo representar el nuevo teatro de enseñanza: "By the eighteenth century the middle class accepted the need to bring the lower classes within its system of surveillance [...] should ban those popular theatrical pieces [...] should only be excluded from the theater obliquely through the raising of prices" (Malcom K. Read, Language, Text, Subject: A Critique of Hispanism, Purdue University, West Lafayette, 1992, p. 115).

2. Juan Menéndez Peláez y Carla Menéndez Fernández, “Teatro y pedagogía: el sustrato didáctico de Ifigenia", Iphigenia. Tragedia escrita en francés por Juan Racine y traducida al español por D. Gaspar de Jove Y Llanos, ed. Jesús Menéndez Peláez, Fundación Foro Jovellanos del Principado de Asturias-Cajastur, Gijón, 2007, p. 54. "Jovellanos pasará de la teoría a la práctica con dos obras que forman parte del canon dramático 
enseñanza tenía que incluir las reglas clásicas para el teatro que el Siglo de Oro había olvidado, pero que los franceses recuperan: "pero si viviese [Horacio] en este día, y nos diese reglas, acaso nos mandaría que leyésemos a Racine y Voltaire"3. Resumiendo, de manera coherente y lúcida las motivaciones que llevaron a esta traducción de Ifigenia, Josep M. Sala Valldaura explica que es parte de un programa que "se había puesto en marcha en favor de la nación y de la cultura, del amor patrio y el prestigio, de la dignificación política, social, artística y moral, sin que se pueda diferenciar con claridad un concepto de otro" 4 .

Qué mejor manera de llevar a cabo esta dignificación artística que a través de una obra cuya genealogía era impecable. Se trata de una de las grandes tragedias de Eurípides, Ifgenia en Aulis, que Racine transforma para el escenario francés. Representada por primera vez en Versalles el 18 de agosto de 1674, luego para un público más amplio en el Hôtel de Bourgogne, la Iphigénie de Jean Racine fue un gran éxito en su momento, aunque hoy día yace algo menos preciada ${ }^{5}$. La obra se centra en un sacrificio humano que requiere la diosa Artemis/Diana para que los griegos puedan continuar su viaje a Troya. En la versión de Racine, tal sacrificio recordaría el bíblico de Isaac. Tales sacrificios pueden evitarse con una sustitución: el carnero por Isaac y un venado por Ifigenia. Pero el dramaturgo francés no acepta ni la sustitución animal ni la muerte de Iphigéne. El sacerdote Calchas se da cuenta, en el último momento, que quien debe de ser sacrificada es Ériphile, hija de Teseo y Elena, personaje ausente en Eurípides. En el prefacio a la obra, Racine explica por qué escoge esta tercera y menos conocida solución ${ }^{6}$. A pesar

en la historia del teatro español: Pelayo y El delincuente honrado. En las dos utilizará el teatro para llevar a cabo su programa de reforma ilustrada" (Menéndez Peláez y Menéndez Fernández, Iphigenia, p. 55). La primera, ideada ya en el año en que hizo su traducción de Ifigenia, tiene propósito didáctico: "El didactismo que se pretende lograr parece ser la exaltación de un patriotismo nacional de raigambre astur" (p. 57). La segunda trata de modificar las leyes de duelos y su injusticia.

3. Gaspar Melchor de Jovellanos, "Borrador del prólogo al Pelayo", Obras Completas, ed. José Miguel Caso González, Instituto Feijoo de Estudios del Siglo XVIII-Ayuntamiento de Gijón, Oviedo, 1984, pp. 359360.

4. Josep Maria Sala Valldaura, "La Ifigenia y la tragedia en el siglo XVIII", Cuadernos de Estudios del Siglo XVIII, 20 (2010), p. 138.

5. "Si la tragédie d'Iphigénie connut, du vivant de Racine, un 'inmense' et 'éclatant' succès, force nous est de reconnaître qu'aujourd'hui son étoile est considérablement pâli" (Gérard Defaux, "Violence et passion dans l'Iphigénie de Racine", French Forum, 9.2 (1984), p. 162).

6. En el prefacio a su obra Racine rechaza para su tragedia la muerte de Iphigénie representada por autores tales como Esquilo, Sófocles, Lucrecio y Horacio. También rechaza la sustitución animal en Eurípides y Ovidio. Explica que su tragedia no podía condenar a Iphigénie ya que es modelo de virtud: "Quelle apparence que j'eusse souillé la scène par le meurtre horrible d'une personne aussi vertueuse et aussi aimable qu'il fallait représenter Iphigénie?" (Jean Racine, Iphigéne. Oeuvres de Racine, Le Normant, Paris, 1808, vol. 4, p. 135). Es así que escoge la tercera opción presentada por Pausanias, donde se encuentra una segunda Iphigéne, la hija de Teseo que sí puede ser heroína trágica: "mérite en quelque façon d'être punie, sans être pourtant tout à fait indigne de compassion" (p. 136). La obra de Racine se desvía del final de Euripides, pues tal conclusión no sería aceptada en la Francia del diesisiete como algo trágico. Al recomponer el final, 
de los razonamientos de Racine, casi parece como si se tratara de un final falso que resta dignidad a la obra ${ }^{7}$. Cabe preguntarse por qué utiliza Jovellanos esta obra de Racine que titubea en sus tonos trágicos para ejercitar la traducción de un clásico de una manera fidedigna ${ }^{8}$. Lo que sí constatamos es la transformación del alejandrino francés al verso endecasílabo, algo clave para Jovellanos quien prefería éste al alejandrino que se vuelve "inaguantable" en textos extensos?.

El endecasílabo nos lleva a la premisa central de este breve ensayo: la influencia de Boscán en Jovellanos, y la cuestión de por qué Jovellanos escoge esta tragedia de Racine. Sala Valldaura ha afirmado que el programa de Jovellanos se fundamenta en diversas nociones, entre ellas la dignificación artística y moral. Ya hemos constatado lo artístico, ya que el endecasílabo cae dentro de este tipo de dignificación, superando al alejandrino francés. Jovellanos es muy consciente de quiénes fueron los poetas españoles que primero introdujeron el endecasílabo en España, Garcilaso de la Vega y Juan Boscán, y así los menciona en sus obras. Es curioso que Jean-Pierre Clément, en su estudio de las lecturas de Jovellanos, deje de lado a Boscán. Subraya que Jovellanos, en su Memorias del Castillo de Bellver, llama a Garcilaso un Horacio español. Añade: "generalmente se publicaban estas Obras [de Garcilaso] con las Poesías de Boscán; Palau señala 16 eds. de este tipo entre 1543 y 1658; es probable que Jovino poseía una de ellas" ${ }^{10}$. Pero Jovellanos sí se refiere a Boscán en sus obras; y, en las memorias de la vida de Jovellanos, Juan Agustín Ceán Bermúdez reitera la importancia de estos poetas para nuestro autor: "Pero la reflexiva lectura de don Gaspar en los mejores autores latinos, en los escogidos italianos, en los dramáticos franceses, en los exaltados ingleses y en los nuestros armoniosos Garcilaso, Boscán, Herrera, Argensolas y León, le separó de tan mal camino"11. Quisiéramos

Racine "peut a la fois retablir la gloire de son illustre prédéceseur, et faire sa critique pour enfin doubler son propre prestige en faissant mieux que son maitre" (Francoise Jaouen, "Iphigénie: poétique et politique du sacrifice", Littérature, 103 (1996), p. 19).

7. Hasta las últimas cuatro décadas, se condenaba este final. Francois Granet, por ejemplo, explica que "le personnage d'Eriphile est absolument inutile; il est vicieux, puis qu'il donne a la piéce une fin qu'elle ne dois pas avoire" (Francois Granet, "Remarques sur l'Iphigénie de Monsieur Racine", Recueil des dissertations sur plusieurs tragédies de Corneille et de Racine, Georg Olms Verlag, Hildesheim, NY, 1975, p. 334). Lucien Goldman Lucien Goldman hace eco de este razonamiento afirmando la "faiblesse esthétique de la piece" (Lucien Goldman, Le Dieu Caché, Gallimard, Paris, 1959, p. 406).

8. "Y se trata de una tradición que sigue muy de cerca al texto original: a pesar de estar sometida a un leve proceso reductor, representado por la también leve pérdida de materia verbal y semántica cuantificada arriba, es «bastante fiel» al original de Racine, que el traductor no ha suprimido nada esencial y que grosso modo se ha dado cumplido traslado de los contenidos, sin que se pueda sostener que se trate de una traducción literal" (José María Fernández Cardo, "De Racine a Jovellanos: Estudio de la traducción de Ifigenia", Iphigenia. Tragedia escrita en francés por Juan Racine, p. 96).

9. José María Caso González, La poética de Jovellanos, Prensa Española, Madrid, 1972, p. 134; y José María Fernández Cardo, “De Racine a Jovellanos...”, pp. 99-100.

10. Jean Pierre Clément, Las lecturas de Jovellanos, Imprenta La Cruz, Oviedo, 1980, p. 22.

11. Juan Agustín Ceán Bermúdez, Memorias para la vida del Excmo. Señor D. Gaspar Melchor de Jove Llanos, y noticias analiticas de sus obras, por, con licencia del Gobierno, Imprenta que fue de Fuentenebro, Madrid, 
entonces mostrar aquí que la lectura de Boscán puede haber influenciado a Jovellanos en su selección de un tópico que le gustaría traducir. O sea, pensamos que los versos de Boscán sobre el sacrificio de Iphigenia, escritos en endecasílabos, pueden haber incitado a Jovellanos a escoger a Ifigenia entre las muchas obras de Racine ${ }^{12}$.

Y es que Jovellanos sabría muy bien que Boscán fue el que popularizó el endecasílabo en España. Recordemos que este poeta catalán, después de su conversación en 1526 con el embajador Veneciano Andrea Navagero, decidió experimentar con el endecasílabo italiano, también consiguiendo la ayuda de Garcilaso en este proyecto ${ }^{13}$. Para Boscán, el endecasílabo es muy superior a la métrica nativa ya que recuerda los versos de la antigüedad clásica y muestra "una disposición muy capaz para recibir cualquier materia; o grave o sotil, o dificultosa o fácil, y asimismo para ayuntarse con cualquier estilo"14. Ignacio Navarrete y Javier Lorenzo han subrayado que Boscán lo considera un verso aristocrático: Lorenzo analiza "la variedad de estrategias que Boscán utiliza para establecer la preeminencia social del verso italiano y su adhesión a los principios de la doctrina aristocrática y cortesana"15; Navarrete se centra en la genealogía de este tipo de verso, pues le da autoridad: "Thus, the genealogy asserts for the hendecasyllable an ancestry in Greco-Roman antiquity, not unlike that of knights in romances, while the origins of the Castilian forms, like that of people hiding their Jewish ancestry, cannot be traced [...] The repeated assertions of nobility for the new genres and their practitioners constitute one of the principal recurrent themes in Boscán's preface"16. Es justamente este deseo de dejar atrás el vulgo e ir en busca de algo nuevo, pero con noble genealogía, lo que acerca a Jovellanos al endecasílabo. Si Boscán lo utiliza para recobrar temas de la antigüedad clásica, así también lo hará Jovellanos.

Además de interesarse por el endecasílabo de Boscán, es posible que Jovellanos, tan atento a realzar la literatura asturiana, se haya dado cuenta de que Boscán estaba siendo menospreciado por ser poeta catalán. Aunque fue él quien dividió su obra (publicada póstumamente) en cuatro libros, incluyendo a Garcilaso en el cuarto, la popularidad del poeta catalán fue poco a poco apagándose. Carlos Clavería asevera: "alcanzado el

1814 , p. 289.

12. Cuando nos referimos al personaje de Racine escribimos Iphigénie, cuando se trata de Boscán, escribimos Iphigenia, y cuando nos referimos a Jovellanos usamos Ifigenia. Jovellanos, al igual que Boscán, escribe Iphigenia, pero la edición moderna de la obra corrige el nombre a Ifigenia. Lo mismo hacemos con Eriphile / Erifile.

13. En la carta a la duquesa de Soma, que encabeza el tercer libro de sus obras, Boscán escribe: "Porque estando un día en Granada con el Navagero [...] me dixo por qué no provava en lengua castellana sonetos y otras artes de trovas usadas por los buenos autores de Italia" (Juan Boscán, Obra completa, ed. Carlos Clavería, Cátedra, Madrid, 1999, p. 118).

14. Boscán, Obra completa, p. 119.

15. Javier Lorenzo, "Poética e ideología: la aristocratización del endecasílabo en la 'Carta a la duquesa de Soma”, Hispanic Review, 73.1 (2005), p. 25.

16. Ignacio Navarrete, Orphans of Petrarch: Poetry and Theory in the Spanish Renaissance, University of California, Berkeley-Los Angeles, 1994, p. 61. 
año 1600, los dos amigos sólo fueron juntos en la apreciación de algún crítico"17. Y es que las obras de cada uno se comenzaron a publicar por separado. Mientras más se leía y comentaba a Garcilaso, más se olvidaba a Boscán. Explica Javier Lorenzo: "Este esfuerzo sistemático de postergación crítica está estrechamente relacionado [...] con el modelo imperial, aristocrático y castellanista de nación que instaura en España la dinastía Habsburgo"18. Mientras se alaba a Garcilaso, "la imagen tradicional de Boscán como poeta extranjero, incompetente, aburguesado y desconocedor de los clásicos" impide que su obra sea tan aclamada ${ }^{19}$. Pero, como constataría Jovellanos, la poesía de Boscán muestra un extenso y profundo conocimiento de los clásicos ${ }^{20}$. Puede muy bien que al rescatar la Iphigénie de Racine, esté Jovellanos señalando con sigilo que se deben leer otros textos sobre esta figura $-y$ sobre todo el poema clasicista de Boscán ${ }^{21}$. Carlos Clavería asegura que "el lector de hoy, si paciente llega hasta el Libro III de sus obras, encontrará encantos nada despreciables", incluyendo el Leandro, imitación de Museo con elementos de Virgilio y Hesíodo ${ }^{22}$. Añade que: "El segundo placer que encontrará quien llegue al Libro III será el 'Capítulo', un poema de reflexión amorosa al estilo de Petrarca y que además incorpora un fragmento de literatura clásica: el sacrificio de Ifigenia, en otro gesto relevante de información que obliga al crítico a la rebusca de fuentes [...]"23.

Este Capitulo de Boscán escrito en tercetos (endecasílabos) podría pasar desapercibido, siendo muy convencional en su tema y sus imágenes petrarquistas. Aquí tenemos la crueldad de la dama ${ }^{24}$, junto con las tristezas, dolores y tormentos del amante ${ }^{25}$. Todo parece algo formulario hasta el verso 289. Aquí la voz poética decide "contar cuentos pasados" 26 para consolarse. La última cuarta parte del Capitulo, entonces, es algo sor-

17. Boscán, Obra completa, p. 16.

18. Javier Lorenzo, Nuevos casos, nuevas artes: intertextualidad, autorrepresentación e ideología en la obra de Juan Boscán, Peter Lang, New York, 2007, p. 9.

19. Lorenzo, Nuevos casos, nuevas artes, p. 9.

20. Sobre el uso de los clásicos en el Capítulo de Boscán y el impacto de la écfrasis de Timantes en el Renacimiento y en el Siglo de Oro español, véase Frederick A. de Armas, "Un pintor clásico en la poesía del Siglo de Oro: Timantes en Boscán, Garcilaso, Lope de Vega y Argensola", Serenísima palabra: Actas del X Congreso de la Asociación Internacional Siglo de Oro (Venecia, 14-18 de Julio 2014), ed. Ana Bognolo et al., Edizione Ca’Foscari, Venezia, 2017, pp. 49-67.

21. Por otra parte, Jovellanos no habría recomendado la versión de José de Cañizares titulada El sacrificio de Ifigenia. Ana Cristina Tolivar Alas apunta el abanico de posibilidades en estas traducciones y adaptaciones de Racine: "desde la de Cańizares, plenamente barroca, pasando por las versiones pre-ilustradas de Llaguno o de Juan de Trigueros y por las de estilo rococó" (Ana Cristina Tolivar Alas, "El teatro de Racine en la España de los primeros Borbones", Teatro y traducción, ed. Francisco Lafarga y Roberto Dengler, Universitat Pompeu Fabra, Barcelona, 1995, p. 62).

22. Boscán, Obra completa, p. 20.

23. Boscán, Obra completa, p. 21.

24. Boscán, Obra completa, p. 326, v. 25.

25. Boscán, Obra completa, p. 334, vv. 240, 242.

26. Boscán, Obra completa, p. 336, v. 292. 
prendente según explicó Menéndez Pelayo ya hace un siglo: "Parece que una brisa venida de las playas de la antigüedad refresca nuestra mente cansada [...] del escolasticismo amoroso" ${ }^{27}$. Es aquí, en unas treinta estrofas, donde se recuerdan los eventos del sacrificio de Ifigenia, teniendo como base la famosa pintura clásica de Timantes sobre este sacrificio, que, aunque perdida, se conocía a través de la descripción de Plinio, quien, en el libro 35 de su monumental Historia natural, incluye una detallada historia de la pintura greco-latina ${ }^{28}$. Boscán recalca que está recordando "aquel pintor del triste sacrificio" 29.

No cabe duda de que hay grandes diferencias entre la "pintura" de Boscán y la tragedia de Jovellanos, ya que este último está traduciendo de manera libre a Racine quien, como ya se ha dicho, transforma la tragedia de Eurípides. Pero estoy convencido de que el lenguaje de la obra de Jovellanos no solo refleja el vocabulario de Racine sino que puede recordar a Boscán ${ }^{30}$. Es cierto que desde un principio se notan grandes diferencias entre ambas obras y es así como debe de ser ya que utilizan modelos muy diferentes. En Boscán, el amante, recordando la pintura, explica que Iphigenia debe de ser sacrificada para calmar el temporal y viento que detienen a la flota griega. Al contrario, en Eurípides y Racine, es la falta de viento lo que impide la marcha. Sólo podrán continuar el viaje con un sacrificio. En Eurípides y Racine, Agamenón no conlleva suficiente admiración y decoro para ser héroe trágico, pues se muestra incapaz de actuar ante el hecho de que debe sacrificar a su hija. Para Boscán, Agamenón sí es trágico. Siguiendo la pintura que compara los afectos de todos los tristes ante el sacrificio de Iphigenia, esconde el dolor y tristeza del padre con un manto, ya que es imposible describirla: "acordó de pintalle, el buen maestro, / la cabeça cubierta con un manto" ${ }^{31}$. Mientras que Boscán divide el sentimiento trágico entre padre e hijo, no así Racine donde Ifigenia sobresale, como ya bien demuestra el título de la obra. Los muchos desacuerdos entre Agamenón, Clitemnestra, Aquiles y Ulises en Racine, contrastan con la clara visión de Ifigenia / Iphigénie. Ella muestra su valor al aceptar su destino ${ }^{32}$. En el quinto acto de la traducción de Jovellanos, aunque lamentándose, acepta su destino:

27. Marcelino Menéndez Pelayo, Juan Boscán, Librería de los sucesores de Hernando, Madrid, 1919, p. 311. 28. Aunque la pintura ha desaparecido, se ha descubierto en Pompeya un mosaico que debe tener muchos parecidos. En el Renacimiento, se intenta pintar de nuevo la obra de Timantes utilizando las descripciones existentes. Giorgio Vasari pinta al artista pintado esta pintura en su casa de Arezzo. Timantes está dándole los últimos toques al Sacrificio de Ifigenia. En los cielos, se percibe a la diosa Diana observando el sacrificio. La figura velada de Agamenón está en el mismo centro de la pintura, mientras que hombres y mujeres, rodean a Ifigenia, sentada sobre el altar, con los ojos vendados (Liana de Girolamo Cheney, The Homes of Giorgio Vasari, Peter Lang, New York, 2006, p. 152).

29. Boscán, Obra completa, p. 336, v. 290.

30. No podemos, en este breve ensayo, incluir una comparación detallada entre Racine y Jovellanos. Incluiremos solamente unos ejemplos para mostrar cómo se desvía de Racine e imita a Boscán.

31. Boscán, Obra completa, vv. 338, 359-360.

32. Christina Elliott Sorum, en su estudio de la obra de Eurípides, recalca el contraste: "the base motives of the perpetrators of the war and the noble ideals expounded by the maiden who allows it to come about" (Christina Elliott Sorum, "Myth, Choice and Meaning in Euripides' Iphigenia at Aulis", The American Jour- 
¡Oh sentencia! ¡oh rigor inexplicable!

¡dulces Dioses! Vosotros, más benignos,

os contentáis con derramar mi sangre.

Yo obedezco; tomadla... ${ }^{33}$

Aunque Aquiles trate de disuadirla, ella rechaza toda ayuda pues sabe que su sacrificio permitirá que Aquiles triunfe en la guerra de Troya: "juntará a vuestros hechos inmortale(s) / la fama mi memoria" 34 . Mientras que en Eurípides la diosa Artemis / Diana evita el sacrificio trocando a Ifigenia con un ciervo y mientras en Racine se troca Iphigénie por Eriphile, en Boscán el sacrificio se representa con todo su dolor trágico.

Puede que Jovellanos haya simpatizado por esta solución del poeta catalán. Pero de esto nada sabemos. Boscán, que ya había recalcado el dolor y la tristeza que le causaba su amada, pasa a describir un dolor verdaderamente trágico. Aunque la palabra "triste" sea casi imprescindible para describir estos eventos, llama la atención el repetido uso del término en Boscán y Jovellanos. Ambos apuntan la tristeza de Clitemnestra. Mientras que en Boscán leemos "conoció que en la triste madre"35; Jovellanos escribe " $\mathrm{OH}$ madre triste!"36. La tristeza y el lloro se mencionan en una misma frase en el poeta catalán: "no llorando, la triste, mas muriendo"37; y de igual manera en el asturiano: "triste llanto" 38 . Boscán también combina "triste" con "desdichado" en "[...] triste Iphigenia, / hija d'Agamenón, rey desdichado" ${ }^{39}$. En Jovellanos, Agamenón explica a Calcas que su hija, sin saber su destino, está al llegar: "la desdichada / triste Ifigenia" ${ }^{0}$. Son palabras tomadas de Boscán ya que no hay nada parecido en Racine: "Ma fille, qui s’approche, et court à son trépas; / Qui, loin de soupçonner un arrêt si sévère, / Peut-être s'applaudit des bontés de son père” ${ }^{11}$. De allí que mucho de lo triste en Jovellanos emerge de Boscán ${ }^{42}$. De igual

nal of Philology, 113.4 (1992), p. 527). Por otra parte, John Lippitt, es su estudio sobre Kierkegaard, explica que este filósofo considera que Agamenón es el héroe trágico en Euripides, aunque no pueda decidirse a sacrificar a su hija: "Agamemnon does not give the necessary command [...] But the point is that, like Abraham, Agamemnon is prepared to go through with it" (John Lippitt, The Routledge Philosophy Guide Book to Kierkegaard and Fear and Trembling, Routledge, London-New York, 2004, p. 97).

33. Gaspar Melchor de Jovellanos, Iphigenia. Tragedia escrita en francés por Juan Racine, p. 198, vv. 16951698.

34. Jovellanos, Iphigenia, p. 200, vv. 1746-1747.

35. Boscán, Obra completa, p. 338, v. 355.

36. Jovellanos, Iphigenia, p. 207, v. 1919.

37. Boscán, Obra completa, p. 338, v. 350.

38. Jovellanos, Iphigenia, p. 173, v. 1152.

39. Boscán, Obra completa, p. 337, v. 313-314.

40. Jovellanos, Iphigenia, p. 126, vv. 136-137.

41. Racine, 163.

42. La palabra triste recurre a través de los cinco actos de la traducción de Jovellanos. Por ejemplo: "triste aviso" (Jovellanos, Iphigenia, p. 123, v. 41), "triste sacrificio" (pp. 134, 198, 193, vv. 360, 1622, 1692), 
manera, el término dolor aparece en ambos escritores, cuatro veces en Boscán y quince en Jovellanos.

Bien se podría argüir que cada escritor puede estar apoyándose en su modelo, sea Plinio o Racine. También se puede apuntar al modo totalmente distinto en que se incluye a Ifigenia como rima asonante. Mientras que Boscán prefiere la rima e/i, Jovellanos prefiere conceptualizar a Ifigenia con asonancia de e/a ${ }^{43}$. Pero, al desviarse de Boscán, Jovellanos también se aparta de Racine quien utiliza la rima ie: Iphigénie / unie; tyrannie / Iphigénie ${ }^{44}$. Por otra parte, toda una serie de términos compartidos nos hacen pensar que Jovellanos se inspiró en parte en Boscán. Para Boscán, el sacerdote Calchas es "cruel verdugo" ${ }^{4}$. Igual leemos en Jovellanos, donde un Aquiles furioso se refiere a la "sangre de vuestros bárbaros verdugos" ${ }^{36}$. En el acto tercero, Aquiles está rechazando su rol en la tragedia: " ¿ $\ldots$.. que vuestro mismo esposo sea vuestro verdugo? ${ }^{47}$. Hasta otros personajes se contaminan con este término. Clitemnestra acusa a Agamenón de ser "iverdugo de tu hija!" ${ }^{8}$. Las acciones del verdugo Calchas y de todos aquellos que asienten al sacrificio, se califican de crueles. En Jovellanos hay quejas contra el "cielo cruel”9 y el "cruel esposo" ${ }^{50}$, entre otras. Boscán es más directo: "cruel verdugo" ${ }^{1}$. Ambos personifican el instrumento del sacrificio, acusándolo de ser cruel: "cruel cuchillo" ${ }^{2}$, exclama Boscán; "con levantar sobre un altar funesto / el cruel hierro"53, se queja Aquiles en Jovellanos ${ }^{54}$. También el mismo sacrificio se visualiza de forma parecida por parte de los dos escritores, resaltando el cuello de Ifigenia. Mientras que en Jovellanos se imagina el sacrificio ("un repentino golpe cortaría / vuestro cuello inocente y humillado"55), en Boscán

"triste llanto" (p. 173, v. 1152) “oráculo tan triste" (p. 178, v. 1251), "triste golpe” (p. 192, v. 1600), "triste padre" (p. 200, v. 1729).

43. Ejemplos en Jovellanos: Ifigenia / cadenas (p. 142, vv. 503, 505); Ifigenia / penas (p. 143, vv. 555, 57); Ifigenia / extrañeza (p. 156, vv. 815, 817); Ifigenia / fineza (p. 157, vv. 831, 833); Ifigenia / estrella (p. 158, vv. 854, 856). Boscán rima Iphigenia con perdía (pp. 336-337, vv. 313, 315), lo que puede recordar un par de rimas en Jovellanos: Ifigenia / presencia (p. 145, vv. 585, 587); Ifigenia / clemencia (p. 154, vv. 769, 771), aunque nunca con rima aguda.

44. Racine, 199.

45. Boscán, Obra completa, p. 320.

46. Jovellanos, Iphigenia, p. 202, v. 1803.

47. Jovellanos, Iphigenia, p. 171, vv. 1113-1114.

48. Jovellanos, Iphigenia, p. 185, v. 1401.

49. Jovellanos, Iphigenia, p. 135, v. 371.

50. Jovellanos, Iphigenia, p. 168, v. 1039.

51. Boscán, Obra completa, p. 337, v. 320.

52. Boscán, Obra completa, p. 336, v. 312.

53. Jovellanos, Iphigenia, p. 171, v. 1104.

54. En el texto francés falta el término cruel: "C'est peu que de vouloir, sous un couteau mortel, / Me montrer votre cour fumant sur un autel” (Racine, p. 259).

55. Jovellanos, Iphigenia, p. 171, vv. 1119-1120. 
ya observamos la realidad del sacrificio ("Cuando aquel virginal cuello cortado / fue [...]"56). En Racine, lo corporal se censura ya que falta la mención del cuello: "Et d'un fer imprévu vous tomberiez frappée" 57 .

Por último, no debe olvidarse la importancia de los celos. Racine, como ya hemos observado, añade el personaje de Eriphile. Ella conoce muy bien sus orígenes troyanos y así debería de odiar a los griegos. Pero no es así: se enamora de Aquiles. Katherine E. Wheatley explica: "She has a pride of race which intensifies her feelings of guilt. It is not without self-reproach that she yields to the jealousy which causes her to hate her kind benefactress Iphigénie, but she is driven by an unconquerable impulse to destroy her rival" ${ }^{\prime 2}$. O sea, Racine ha construido un personaje con tanto conflicto interno que para nada puede parecer positivo a lectores o espectadores ${ }^{59}$. Que este personaje sea el que es sacrificado al final puede que anule mucho de lo trágico a la obra. Eriphile sabe que debe de odiar a Aquiles, pero le ama; al mismo tiempo sabe que debe mostrarse agradecida para con Iphigénie, pero la odia y quiere destruirla. El público puede comprender muy bien que Iphigéne se muestre celosa de Eriphile, pero nunca lo contrario. Aun así, Roland Barthes, $\mathrm{y}$ otros muchos que aceptan sus ideas, la consideran la figura trágica de la obra: "la tragédie est ici tout entière réfugiée dans Ériphile [...] son être est la jalousie des dieux" ${ }^{\prime \prime}$. Desde un principio ella estaba destinada a morir sacrificada. Todo su dolor, todo su conflicto, esconde una realidad trágica. Explica Andre Green que "Eriphile is doomed to misfortune: the misfortune she causes others is no more than a slight deflection of the misfortune that must devolve on her" ${ }^{\text {"61. }}$. O sea, desde un principio de la obra, Racine establece un desvío en el que todos se duelen por alguien que en realidad no va a ser personaje trágico. En Boscán no hay tal desviación. Desde que se introduce el mito clásico, está claro que Ifigenia va a morir, que todo el dolor y toda la tristeza le pertenece, aunque los comparta con su dolorido padre. En Racine y Jovellanos, tales sentimientos, juntos con la lástima, son prestados. Aunque no hay extravío en lo trágico, Boscán sí se desvía al final de su poema. Explica que había querido pintar los $\operatorname{celos}^{62}$, pero que, al ser su dolor tan excesivo "faltó el pinzel, faltaron los colores" ${ }^{3}$. Al igual que Agamenón, esconde su rostro pues no puede mostrarse dolor tan excesivo, Boscán oculta el dolor

56. Boscán, Obra completa, p. 337, vv. 328-329.

57. Racine, p. 240.

58. Katherine E. Wheatley, Racine and English Classicism, University of Texas Press, Austin, 1956, p. 317.

59. Por ejemplo, exclama Erifile: "Veo con harta envidia que Ifigenia / es la tierna delicia de su padre, / mientras yo vivo mísera y expuesta" (Jovellanos, Iphigenia, p. 140, vv. 457-459).

60. Roland Barthes, Sur Racine, Seuil, Paris, 1963, p. 109.

61. André Green, The Tragic Effect: The Oedipus Complex in Tragedy, trad. Alan Sheridan, Cambridge University, Cambridge, 1979, p. 160.

62. Boscán, Obra completa, p. 339, v. 373.

63. Boscán, Obra completa, p. 339, v. 376. 
que le causan los celos. Todo ese dolor que siente la voz poética se esconde y se muestra en la pintura o historia de Ifigenia y el sufrir de su sacrificio.

Jovellanos, admirador del endecasílabo y lector de Boscán debe de haber admirado el Capitulo del poeta catalán. Aquí se dignifica la palabra, el verso y el sentido trágico. Se utiliza de manera inventiva a los clásicos. Puede que al decidir qué obra de Racine quiere traducir, haya recordado la Iphigenia de Boscán y así decidido su tema. Al traducir a Racine, Jovellanos preserva el sentido del original, pero no se trata de una traducción metafrástica o literal. Jovellanos intenta preservar el sentido del original, pero modifica motes, frases, sintaxis, versificación, etc. Utiliza tantos motes y expresiones ya existentes en el poeta catalán que quisiéramos afirmar que lo recordaba mientras traducía. Al igual que en Boscán, hallamos en esta elegante traducción de Racine la mezcla de estilo y materias algo tan apreciado en el endecasílabo. Se resalta también el dolor y la tristeza de modos muy similares. En ambos, el verdugo es cruel y muestra su herramienta, también cruel, con la que amenaza el cuello de Ifigenia, subrayando lo corpóreo. Ambos, Boscán y Jovellanos, invocando los celos y los cielos, se desvían de lo que parece ser la tragedia $^{64}$. Si en Boscán el sacrificio de Iphigenia es un velo que esconde el dolor de los celos del poeta, en Jovellanos, los pérfidos celos de Eriphile esconden su sino trágico. En este breve ensayo hemos querido pintar a Jovellanos, lamentándose del olvido en que caía un poeta catalán, intentando recobrar sus palabras, sentidos y sentimientos. Hemos querido pintarlo con Racine en frente, pero con Boscán a su lado, aunque escondido y con un manto.

64. En ambas obras hay un desasosiego asociado a la crueldad de los cielos y al horrible sacrificio que se exige. Boscán apunta a "la fealdad del maleficio" (p. 338, v. 345). En Jovellanos Clitemnestra se asombra y escandaliza ante la imagen del sacrificio y ante la crueldad de los cielos:

¿Qué? ¡Un sacerdote a vista de las tropas

clavará de Ifigenia el vil acero,

le abrirá el pecho y con curiosos ojos

en su rasgado y palpitante seno

se informará del gusto de los Dioses! (Jovellanos, Iphigenia, p. 186, vv. 1455-1459). 